\title{
A atuação da/o assistente social nos casos de alienação parental
}

\section{The social worker's performance in cases of parental alienation}

\author{
Thais Tononi Batista \\ Assistente social e mestre em Política Social pela UFES; \\ atua no Tribunal de Justiça do Espírito Santo; Vitória, Brasil. \\ thaistononi@hotmail.com
}

Resumo: O artigo é parte da pesquisa de mestrado intitulada Judicialização dos conflitos intrafamiliares: considerações do Serviço Social sobre a alienação parental. O tema é tratado sob uma perspectiva crítica de análise, conjugando-se algumas análises teóricas à pesquisa empírica realizada com (as)os profissionais. ${ }^{1}$ Compreende-se que é fundamental avançarmos na discussão do tema aliando-o ao debate do projeto ético-político da profissão, refletindo os limites e as possibilidades da atuação profissional.

Palavras-chave: Alienação parental. Serviço Social. Projeto ético-político.

\begin{abstract}
This article is part of a master's degree research called "Judicialization of intrafamily conflicts: Social Service considerations about parental alienation." The theme is dealt with a critical perspective of analysis, combining theoretical analyses and empirical research carried out with the professionals. We understand that it is fundamental to advance in the discussion of such a theme, linking it to the debate of the ethical-political project of the profession, besides thinking about the limits and possibilities of the professional performance.
\end{abstract}

Keywords: Parental alienation. Social Service. Ethical-political project.

\section{Introdução}

O objetivo deste artigo consiste em discutir o tema da alienação parental, buscando recuperar elementos de análise importantes para as(os) assistentes

1. A coleta de dados ocorreu por meio da aplicação de questionário on-line junto aos profissionais que atuam nas Centrais de Apoio Multidisciplinares do Poder Judiciário do Espírito Santo. Os profissionais lotados nessas CAMs são responsáveis por atender demandas oriundas das Varas de Família, Órfãos e Sucessões, Infância e Juventude e Violência Doméstica. 
sociais, como o Estado, a questão social, as políticas sociais, além do direito e do processo de judicialização. Procuramos conjugar as análises teóricas aos dados empíricos coletados a partir aplicação dos questionários on-line, parte da pesquisa de mestrado. Trata-se de um trabalho qualitativo cujas análises se apoiaram na teoria crítica marxista, aliando-se ainda ao debate elementos do projeto ético-político da profissão. A análise de dados compreendeu três eixos básicos, fundamentalmente atrelados às dimensões da intervenção profissional, a saber: teórico-metodológicos, ético-políticos e técnico-operativos.

As respostas obtidas totalizaram 25 , de um total de 29 profissionais que autorizaram o envio do formulário, num universo de 52 assistentes sociais lotadas(os) nas Centrais de Apoio Multidisciplinares ${ }^{2}$ (CAMs) do Poder Judiciário do Espírito Santo (PJES).

Tratar da alienação parental no âmbito de atuação da(o) assistente social constitui por si só tarefa difícil, e nossa intenção encontra ainda mais percalços haja vista a reduzida produção teórica sobre a temática no cenário brasileiro.

Observamos que em grande parte dos estudos sobre a alienação parental, autores de diferentes áreas do saber têm se ocupado de explorar o contexto social e os papéis parentais, dedicando parte de sua atenção ao debate sobre a família e as mudanças nas relações familiares. Entendemos que tal discussão se faz realmente necessária por ser na família que repercutirão os efeitos das transformações macrossociais que também ressoarão nas individualidades. E é nesse contexto que podemos inserir as análises sobre o primado materno em relação à prole, que afirmam o amor da mãe como algo inato, instintivo à mulher nas sociedades ocidentais contemporâneas e que operam na realidade atribuindo à figura paterna um papel de menor importância cuja capacidade de cuidados com os filhos também seria limitada.

De certo modo, a crença na ideia de que a mulher é quem realiza de forma adequada os cuidados dos filhos, sendo ela predestinada para tal, parece

\footnotetext{
2. As Centrais de Apoio Multidisciplinar têm suas atribuições regulamentadas por meio da Resolução n. 066 de 2011 do PJES e trata de seu funcionamento e estruturação, bem como define as atribuições da equipe técnica. A CAM Cariacica é responsável por atender a seis comarcas nas matérias de família, órfãos e sucessões, violência doméstica, infância e juventude (exceto a comarca sede que é Cariacica, que possui Vara de Infância e Juventude própria).
} 
repercutir nas decisões prolatadas pelo Poder Judiciário de todo o país que ainda garantem, em sua maioria esmagadora, a guarda unilateral dos filhos às mães. Por outro lado, no contexto atual o avanço tecnológico tende a produzir tensões no lugar masculino no seio familiar, pois a comprovação da paternidade possibilitou que os homens passassem a reivindicá-la, o que impactou sobremaneira a relação entre pais e filhos.

Compreendemos que não é possível discutir o tema da alienação parental no âmbito de atuação da(o) assistente social sem que se considere elementos de estudo como o Estado, a questão social, as políticas sociais, a família, o direito e o processo de judicialização. O Estado, que tem assumido cada vez mais uma ação interventiva voltada para penalizar comportamentos e atitudes consideradas transgressoras à ordem, ao mesmo tempo em que se afasta de seu papel de intervenção sobre as expressões da questão social que se espraiam sobre as famílias, sobretudo as mais empobrecidas.

Da mesma forma, não se pode ignorar o papel do Judiciário e a interferência que decisões judiciais ocasionam na vida das pessoas, tendo em vista ainda que a(o) assistente social é uma(um) das(os) profissionais acionadas(o)s para que, com seus conhecimentos técnicos, manifeste-se acerca de várias situações, nesse caso sobre a ocorrência da alienação parental.

\section{Desenvolvimento}

\section{Estado, questão social, politicas sociais: as bases de legitimação e a dimensão teórico-metodológica da profissão}

No âmbito de atuação do Judiciário, a requisição profissional encontra-se relacionada às demandas que são fruto das modificações ocorridas no Brasil, sobretudo nas últimas décadas, a partir da redemocratização, promulgação da Constituição Federal de 1988 e outras legislações de cunho social que se sucederam, bem como da emergência do modelo econômico neoliberal levado a cabo a partir da década de 1990, ante a crise mundial (e cíclica) do capital. Tais mudanças abalaram os direitos conquistados ao longo dos anos, principalmen- 
te a partir da Carta Magna, e têm levado inúmeras pessoas a recorrer ao Poder Judiciário na expectativa de ter seus direitos ressarcidos, constituindo o processo de judicialização.

A perspectiva da judicialização e os limites do próprio Judiciário em relação a esta não passaram despercebidas entre as(os) entrevistadas(os):

A judicialização da alienação parental possibilitou a ampliação do debate sobre a questão. Todavia, salienta-se que o Poder Judiciário, isoladamente e com sua tradicional metodologia de resolução de conflitos, não detém condições em atender essa demanda em virtude de sua complexidade. Isso aumenta a possibilidade de emissão de sentenças sem compromisso com o melhor interesse da criança, dada a limitação de alguns magistrados e a recorrente dificuldade em dialogar com outras áreas de conhecimento além do Direito e, principalmente, acatar os pareceres das(os) profissionais que o auxiliam, tais como os assistentes sociais e psicólogos. (Entrevistada(o) n. 20)

Deve se ter em conta ainda que a atuação profissional na área sociojurídica se encontra entrelaçada em "um misto de aspectos oriundos da questão social com as práticas jurídicas ou judiciárias", o que faz com que sua atuação se veja polarizada "entre os objetivos da instituição de controle, disciplinamento e ajustamento e os da população na possibilidade de terem acesso aos direitos humanos e sociais" (Trindade e Soares, 2009, p. 15).

Conforme destaca Iamamoto (2008), "a questão social se torna a base de justificação" da profissão. Por sua vez, Netto (2005) pondera que as conexões genéticas entre o Serviço Social se dão com as peculiaridades da questão social na sociedade burguesa madura na era dos monopólios.

Assim, buscando compreender se tal elemento é considerado pelas(os) profissionais entrevistadas(os) foi-lhes indagado se nos processos de alienação parental em que atuaram foram identificadas as expressões da questão social. Como resposta, $84 \%$ das(os) profissionais afirmaram que as expressões da questão social compareceram nos processos em que atuaram.

Em relação às expressões da questão social identificadas nos processos, as mais destacadas foram: desemprego/inserção precária no mercado informal (44\%); vulnerabilidade econômica/dificuldades financeiras (32\%); rede de 
serviços insuficientes (saúde, educação, assistência social, defensoria pública) (24\%); pobreza (20\%); dependência química/uso abusivo (20\%), entre outros.

Tais expressões da questão social, apontadas, dentre outras, pelas(os) entrevistadas(os), vão ao encontro das considerações de Valente (2008b), ao destacar que $\mathrm{a}(\mathrm{o})$ profissional deve articular os litígios de família às transformações ocorridas na organização familiar, admitindo-se a existência de novos modos de pensar a diversidade de arranjos vivenciados pelas famílias nas últimas décadas e reconhecendo que tal diversidade se funda na força das mudanças "processadas no mundo do trabalho, perpassando as representações dos papéis de gênero e das funções parentais" (Valente, 2008b, p. 75).

Houve também quem ponderasse acerca da não existência ou preponderância da questão social nos casos de alienação parental atendidos, havendo, no entender da(o) entrevistada(o), um predomínio de questões psicológicas vivenciadas em decorrência da dificuldade de separação entre conjugalidade e parentalidade por parte dos envolvidos na lide. A(o) entrevistado(a) conclui que é importante o Serviço Social discutir mais sobre esse tema.

Penso que o Serviço Social precisa discutir o processo de atuação profissional nos casos que envolvam alienação parental, pois nos casos atendidos até o momento, em apenas em um apareceu as expressões da questão social; nos demais as questões se referiam às dificuldades do pai e/ou mãe em aceitar a ruptura da conjugalidade, onde demandava maior intervenção do ponto de vista psicológico. (Entre$\operatorname{vistada(o)~n.~15)~}$

Ainda sobre a questão social, Netto (2005) adverte que ela por si só não determina a gênese do Serviço Social, mas oferece as bases para tal emergência quando se transforma em objeto de intervenção por parte do Estado.

Nesse sentido, o Estado - importante elemento de análise para a(o) assistente social - é capturado na ordem monopólica e se manifesta "numa nítida fusão entre as funções econômicas e políticas do Estado" (Iamamoto, 2008, p. 169), sendo no contexto atual "tensionado tanto pelas exigências da ordem monopólica, quanto pelos conflitos sociais" (p. 169).

Logo, compreendemos que a categoria Estado não deve estar descolada da compreensão da(o) profissional quando de suas intervenções. No caso em 
estudo, $80 \%$ das(os) entrevistados afirmaram que consideram tal categoria em seus estudos. Ao longo do questionário, encontramos em determinadas passagens elementos que nos permitem fazer algumas inferências sobre tal categoria, apontando para seu caráter normatizador (através de leis) e arbitrário (quando as leis não são discutidas com a população ou setores interessados), além de um caráter interventivo na vida de indivíduos e famílias (não somente por intermédio de leis, mas quando é "chamado" a intervir em situações que "fogem" ao padrão normativo que se espera).

[...] o Estado é chamado a dar suporte institucional à situação exposta [...], buscando elucidar a realidade vivida da família [...]. (Entrevistada(o) n. 10)

A lei é arbitrária, trata as crianças como objeto, privilegia o litígio; e isto é contraditório com o projeto ético-político do Serviço Social quanto a respeito aos usuários, proteção integral aos grupos tradicionalmente hipossuficientes (crianças). (Entrevistada(o) n. 9)

No que se refere às políticas sociais, é por meio delas que o Estado começa a administrar as expressões da questão social, que passa a ser fragmentada em "problemas sociais" (Iamamoto, 2008, p. 170).

Contudo, observa-se que a(o) assistente social que atua no Poder Judiciário não tem sua intervenção direta e imediatamente relacionada à implementação e elaboração de políticas sociais, pois estas cabem ao Executivo estruturar. Mas igualmente a(o) profissional lidará em seu cotidiano com "inúmeras expressões da questão social, que afetam crianças, adolescentes e suas famílias", como destaca Iamamoto (2010, p. 287).

Nesse sentido, torna-se importante identificar se as(os) profissionais consideram as políticas sociais em suas análises ou parecer e qual a importância destas no contexto das intervenções realizadas. Das(os) entrevistadas(os), $88 \%$ informaram que consideram as políticas sociais em suas análises e/ou parecer. As afirmações se voltaram para a importância da articulação com a rede de atendimento, diga-se, com os serviços que compreendem as políticas públicas existentes:

Quando é evidenciado durante os atendimentos que no cotidiano de vida do sujeito atendido comparece alguma (s) expressão(ões) da questão social, muitas 
vezes faz-se necessário a articulação com as políticas públicas (saúde, habilitação, previdência social, educação, assistência social etc.) visando a viabilização dos direitos sociais. (Entrevistada(o) n. 1)

Apontaram ainda para a necessidade de implementação de uma política pública que possa se voltar para a demanda da alienação parental, reconhecendo que esta se constitui uma demanda complexa que necessita de um trabalho articulado, mas que requer também uma abordagem específica:

[...] a alienação configura um fenômeno cuja superação demanda um trabalho de escuta e acolhimento, articulado com outros serviços e profissionais, no intuito de promover o direito e a dignidade da criança. Nesse sentido, os pareceres buscam apontar a necessidade de fortalecimento de políticas públicas capazes de atender essa complexa demanda. (Entrevistada(o) n. 20)

As reflexões que embasam o sentido do Serviço Social no âmbito da problemática em análise apontam que este só se materializa nos marcos do projeto ético-político que orienta a profissão. Assim, essa questão, por ser fundamental, constitui-se em singular objeto de análise em que serão evidenciados os desafios que se colocam para as(os) assistentes sociais que atuam no PJES.

\section{A construção de um projeto ético-político da profissão e a ultrapassagem do conservadorismo}

A análise histórica da profissão remonta à "prevalência de um comportamento conservador", tal qual comenta Iamamoto (2007, p. 35). Tal aspecto, que somente começou a ser questionado no seio da profissão nas décadas de 1950 e 1960, deixou marcas de uma herança conservadora que ainda se faz presente no interior da categoria. Desse modo, assume papel relevante a construção de um projeto que busque ultrapassar os aspectos conservadores que historicamente permeiam a profissão.

De acordo com Netto (1999, p. 4):

Os projetos profissionais apresentam a autoimagem de uma profissão, elegem os valores que a legitimam socialmente, delimitam e priorizam seus objetivos e 
funções, formulam os requisitos (teóricos, práticos e institucionais) para o seu exercício, prescrevem normas para o comportamento dos profissionais e estabelecem as bases das suas relações com os usuários de seus serviços, com as outras profissões e com as organizações e instituições sociais privadas e públicas (inclusive o Estado, a quem cabe o reconhecimento jurídico dos estatutos profissionais).

O projeto de profissão defendido majoritariamente pela categoria traduz uma tomada de posição quanto à recusa das desigualdades, exclusão, arbítrio, autoritarismo e preconceito que acompanham a sociedade liberal contemporânea e que apresentam a realidade como algo inevitável e natural. As(os) assistentes sociais, contrariamente ao que prega a sociedade liberal, assumem uma posição ético-política engajada com a socialização da riqueza produzida, preceito consubstanciado no Código de Ética de 1993.

Nesse contexto, algumas questões foram dirigidas às(aos) entrevistadas(os) relacionadas à materialização do projeto ético-político da profissão. Indagamos se as(os) profissionais consideravam que conseguiam materializar tais princípios éticos em seu cotidiano de trabalho, mais propriamente no contexto de casos de alienação parental. Por $60 \%$ das(os) entrevistadas(os) foi destacado que conseguem materializar totalmente os princípios do projeto ético-político da profissão, ao passo que 36\% informaram que os materializam parcialmente.

As(os) entrevistados que consideram que materializam os princípios do projeto ético-político da profissão destacaram, em sua maioria, que o fazem através do compromisso e do respeito com a autonomia e a liberdade de expressão dos sujeitos, buscando o acesso dos usuários aos seus direitos e às políticas públicas existentes; no compromisso com o aperfeiçoamento profissional constante; no respeito ao usuário e à sua história de vida, buscando superar visões etnocêntricas que culpabilizem e/ou criminalizem os indivíduos; por meio de uma intervenção profissional que procure compreender os contextos social, cultural e econômico das famílias atendidas; através de um atendimento digno e de qualidade; e no respeito à diversidade e combate a toda forma de discriminação, opressão e violação de direitos.

Àquelas(es) profissionais que responderam que materializam parcialmente ou que consideram que não materializam tais princípios, foi solicitado que especificassem os desafios encontrados nesse sentido. As reflexões 
giraram em torno das limitações do fazer profissional reduzido à elaboração de laudos/pareceres; das condições de trabalho das equipes multidisciplinares, pois não atuam somente nas Varas de Família, o que acarreta na qualidade dos serviços prestados; da necessidade de projetos de intervenção voltados para o atendimento às famílias (dentro da instituição e também enquanto política pública); da impossibilidade de se apontar indícios de alienação parental sem que ocorra estudo psicológico conjuntamente; da dificuldade de se estabelecer a articulação com outras categorias em favor da autonomia e da cidadania dos usuários.

Há ainda quem considere que o projeto profissional é um horizonte a ser perseguido, cujo alcance em sua integralidade é impossível nos marcos da ordem burguesa.

A possibilidade de materialização plena dos princípios do projeto ético-político nega a categoria marxista contradição, além de negar que as(os) profissionais possuem uma autonomia relativa frente às instituições nas quais encontram-se inseridas(os). Portanto, acredito que os princípios do projeto ético-político são um horizonte a ser perseguido, porém de alcance integral impossível nos marcos da ordem burguesa. (Entrevistada(o) n. 4)

Diante dos dados, ressalta-se o quão indispensável é para a(o) profissional buscar recuperar a dimensão teleológica de seu exercício profissional a partir de ações que sirvam para contribuir para a concretização dos valores éticos defendidos pela categoria, sem deixar de considerar a relativa autonomia que se impõe mediante as relações e condições de trabalho (Silva, 2012, p. 152).

\section{O exercício profissional, o estudo ou perícia social em casos de alienação parental e a dimensão técnico-operativa da profissão}

Acreditamos que antes de tudo é preciso ter em mente que "todo processo interventivo que caracteriza o trabalho do assistente social está voltado para a busca da realidade humana e social dos seus usuários, que é essencialmente dinâmica, complexa, heterogênea e multifacetada" (Souza, 2006, p. 69). 
E para que possamos intervir de maneira qualificada é preciso ultrapassar o imediatismo, a fragmentação, o senso comum e a falta de criticidade que fazem parte da dinâmica da cotidianidade e que se "repetem automaticamente em face da burocracia institucional" (Barroco e Terra, 2012, p. 73).

$\mathrm{A}(\mathrm{O})$ profissional tem na realização do estudo social ou da perícia e na confecção do respectivo parecer ou laudo social os principais produtos de sua intervenção na área sociojurídica, podendo atuar no sentido da viabilização do acesso a direitos ou simplesmente servir de instrumento para punição e/ou enquadramento dos sujeitos. Portanto, a perícia ou estudo realizado e o parecer emitido pela(o) profissional assumem papel importante, em muitos casos indispensável, para que se chegue a uma decisão judicial de modo que esta seja a mais justa possível em dado contexto.

Pizzol (2006) destaca que "entre as provas possíveis de serem produzidas estão a prova documental, a prova testemunhal e a prova pericial" (p. 24), sendo esta última elaborada por especialista em determinada área do saber e que tem o objetivo de assessorar o juiz no aclaramento de um litígio.

Nesse sentido, torna-se importante analisar a perspectiva teórica na qual se apoiam as(os) profissionais, a qual pode ser observada a partir das considerações que tecem acerca de questões, como a materialização do projeto ético-político (limites e possibilidades) e do fazer profissional.

Sendo assim, é possível constatar que grande parte das falas das(os) profissionais gira em torno da defesa de uma intervenção crítica, que se fundamente nos princípios defendidos pelo projeto profissional. Alguns entrevistados defendem que as(os) assistentes sociais devem buscar nos fundamentos da teoria crítica marxista os elementos necessários para uma leitura qualificada da realidade.

Procuro fazer as mediações sócio-históricas e culturais que medeiam a vida em família [...]. (Entrevistada(o) n. 5)

É imprescindível a conexão entre a questão social e suas diversas manifestações. Manifestações estas que necessitam de uma interpretação à luz de uma visão crítica da realidade, valorizando a historicidade, as contradições e as mediações, buscando na singularidade apresentada alcançarmos o contexto da totalidade. (Entrevistada(o) n. 10) 
Por outro lado, encontramos afirmativas que trazem à tona a histórica ideia de dicotomia teoria/prática que acompanha a profissão desde sua gênese, a qual, atrelada à Igreja católica, trazia consigo a "metodologia de ação" baseada na restrita ideia de empirismo (ver/julgar/agir) como premissa básica de atuação.

Trata-se da dicotomia entre teoria e prática. Por mais que nossos pareceres sejam riquíssimos e explicitem toda a dinâmica familiar com suas evidências e possíveis consequências no que tange ao processo de alienação parental, há sempre o questionamento: e daí? Questiono a materialização do parecer, a materialização da(s) intervenção(ões), como um processo de reflexão para os usuários. (Entrevistada(o) n. 18)

Não é incomum nos depararmos com esse tipo de fala. Contudo, é preciso refletir o que ela significa. Afirmativas como essa expressam, na verdade, uma questão teórica cujo respaldo ocorre pela via da teoria positivista e suas variantes, as quais defendem a separação entre teoria e prática como premissa de análise da realidade. Desse modo, se acreditamos que a teoria é um processo de construção e reconstrução do concreto e que este não pode ser compreendido senão de maneira processual, negamos então a ideia de que ela possa ser apreendida como um manual a ser aplicado na prática.

Prosseguimos abordando com as(os) entrevistadas(os) como percebem seus posicionamentos diante do tema alienação parental ao longo de suas considerações técnicas ou parecer. Questionamos se empregam a expressão "alienação parental", sendo afirmado por $72 \%$ que a utilizam nas considerações ou parecer.

Destacamos uma fala em torno da não utilização do termo "alienação parental":

Sempre que possível procuro não utilizar a expressão alienação parental em meus estudos e pareceres, substituindo-a por reflexões teóricas em torno dos conflitos familiares e/ou das expressões da questão social que se vinculam aos indícios da possível conduta a que a expressão se refere. Nunca utilizo a expressão síndrome da alienação parental por considerá-la inconciliável com minhas apostas ético-políticas. (Entrevistada(o) n. 3) 
A fala da(o) entrevistada(o) evidencia a importância de as(os) profissionais refletirem acerca do emprego de tal terminologia, buscando antes trazer à tona processos reflexivos acerca dos conflitos familiares e das expressões da questão social que constituem a história de vida da família, dando a cada situação contornos específicos que se entrelaçam aos aspectos de ordem macrossocial.

Quanto ao emprego da expressão "síndrome da alienação parental", entendemos que requer ainda mais atenção por parte do Serviço Social, pois remete a uma conceituação médica que extrapola as possibilidades de intervenção profissional.

Do mesmo modo, indagamos às(aos) entrevistadas(os) quanto à utilização da lei da alienação parental ao longo das considerações ou parecer técnico, sendo observado que $52 \%$ das(os) profissionais afirmam fazer uso de tal legislação, enquanto $48 \%$ ponderam que não a empregam.

Outra questão proposta às(aos) entrevistadas(os) compreendeu o "diagnóstico" da alienação parental ou da SAP. A maior parte das(os) profissionais, $80 \%$, indicou que afirma haver indícios, mas não a ocorrência de fato da alienação parental, e 20\% atestaram que não afirmam a ocorrência.

Solicitamos que em caso de resposta afirmativa ou ressaltando os indícios, $a(o)$ entrevistada(o) nos informasse quais indicadores utilizava para tal, como, por exemplo, dificuldade de contato da criança com um dos genitores. Entre os indicadores mais destacados pelas(os) profissionais encontram-se: criação de obstáculos para vinculação entre o filho e o genitor não guardião, dificultando, por exemplo, o acesso à criança/adolescente (visitações) (56\%); desqualificação da imagem do outro genitor no exercício da parentalidade (52\%); constantes mudanças de endereço (24\%).

Cabe ressaltar que mesmo entre as(os) profissionais que afirmaram apontar os indícios da alienação parental, há certo receio em torno de tais afirmações:

Na verdade, evito ao máximo utilizar o termo "alienação parental" em minhas considerações ou pareceres. Isso porque entendo que, conforme a lei, a análise para existência/ocorrência deve ser feita através de perícia psicológica ou biopsicossocial. Caso contrário, podemos incorrer no comprometimento da validade do laudo, que poderá ser posteriormente impugnado. No judiciário do ES, a 
atual demanda de trabalho, associada ao insuficiente e desigual número de servidores e profissionais (de psicologia e serviço social) nas equipes, impede que todos os laudos sejam analisados somente pelo psicólogo ou por equipe multidisciplinar. (Entrevistada(o) n. 23)

Avançamos no sentido de apreender se a partir do conhecimento da lei as(os) profissionais participaram de alguma discussão acerca da normativa em seus locais de trabalho, sendo destacado por $96 \%$ das(os) entrevistadas(os) que já participaram de alguma maneira de tal discussão, embora tenham refletido em vários momentos a importância e a necessidade de aprofundamento do tema por parte do Serviço Social e até mesmo sobre as (im)possibilidades de atuação $\mathrm{da}(\mathrm{o})$ profissional frente à demanda:

Necessário se faz capacitar profissionais da área temática tendo em vista tratar-se de tema novo, ainda em fase de pesquisa, sem produção de estatística. (Entrevis$\operatorname{tada}(0)$ n. 14)

Ao analisarmos a lei tendo como pano de fundo todos os elementos que pontuamos até então, infere-se que a(o) assistente social pode se ver confrontada(o) em relação ao seu papel, até porque a discussão em torno do assunto parece não ter se espraiado sobre a categoria, não tendo sido alvo de análise das(os) profissionais por meio de seus órgãos de classe.

Dessa forma, não fica claro o papel da(o) assistente social, uma vez que a lei aborda a realização de perícia psicológica e/ou biopsicossocial. Contudo, por seu contexto e finalidade, infere-se que as(os) profissionais, por meio da perícia social - a qual compreendemos que necessariamente ocorreria paralelamente às perícias psicológica e médica (levando-se ao pé da letra o texto da lei que denomina perícia biopsicossocial) —, deveriam detectar tais comportamentos elencados como pertinentes ao perfil do "genitor alienador".

Isto posto, foi perguntado às(aos) profissionais se diante do que a lei estabelece, no que tange à intervenção profissional, participaram em algum momento de capacitação específica tal qual a própria normativa preconiza. A totalidade das(os) entrevistados afirmou que não participou de capacitação nesse sentido. 
Para além da capacitação específica a qual faz alusão a referida normativa, procurou-se compreender se as(os) profissionais consideram que a formação profissional ofereceu elementos necessários para a intervenção em casos de alienação parental. Foi informado por $92 \%$ das(os) entrevistadas(os) que não consideram que a formação acadêmica obtida lhes conferiu condições de intervenção em casos de alienação parental.

Esse dado é de suma importância para que possamos compreender o papel $\mathrm{da}(\mathrm{o})$ assistente social em casos de alienação parental. Ora, o que leva as(os) profissionais a pensarem que a formação acadêmica não lhes proporcionou instrumentos para esse tipo de intervenção? O que de fato queremos com nossa intervenção? Seria nosso objetivo profissional diagnosticar a existência da SAP? Mas se a própria lei já se incumbe de elencar um rol de comportamentos e atitudes que indicariam a alienação parental, não bastaria seguir o que está disposto para se concluir a ocorrência ou não da alienação parental ou a instalação ou não da referida síndrome?

Ressaltemos, no entanto, que nos últimos anos o Serviço Social contou com

importantes investimentos acadêmico-profissionais [...] no sentido de se construir uma nova forma de pensar e fazer o Serviço Social, orientadas por uma perspectiva teórico-metodológica apoiada na teoria social crítica e em princípios éticos de um humanismo radicalmente histórico, norteadores do projeto de profissão no Brasil. (Iamamoto, 2004, p. 6)

Reiteramos, portanto, que é indispensável à(ao) profissional retornar aos aspectos teórico-metodológicos, ético-políticos e técnico-operativos, a fim de (re)estabelecer a ligação com o conteúdo profissional que nos orienta.

\section{Considerações}

Compreendemos que muitos são os desafios que perpassam a atuação da(o) assistente social na área sociojurídica, e lidar com processos que tratam da alienação parental não é diferente. As situações que envolvem acusações de alienação parental apresentam-se como desafio às(aos) profissionais do Serviço 
Social, tendo em vista que a realidade é algo extremamente mutável e que tais mudanças vêm impactando de modo a flexibilizar as relações familiares.

No caso da alienação parental, é importante destacar que a ausência de estudos voltados para o tema no âmbito do Serviço Social parece contribuir para que as(os) profissionais se questionem sobre qual a sua "especificidade" na abordagem da problemática. Com isso, muitas vezes deixam de buscar nos elementos historicamente atrelados à profissão, tais como a questão social, suas múltiplas expressões e as políticas sociais, os fundamentos necessários para sua intervenção. Essa ausência de discussão e de acúmulo teórico sobre o tema em específico parece contribuir para que as(os) profissionais não se sintam seguros (ou ao menos se questionem) sobre o que de fato podem fazer.

Diante da responsabilidade ética e técnica da(o) assistente social, devemos considerar algumas habilidades que devem ser incorporadas pela(o) profissional no seu fazer. No contexto da intervenção junto a ex-casais em conflito, é necessário habilidade para lidar com os temores do genitor tido como "alienador", ainda que estes sejam infundados. A(o) assistente social deve ouvi-lo de forma cuidadosa e respeitosa, procurando captar as incoerências presentes em seu discurso, mas sem buscar assumir uma posição como se estivesse "comprando a briga do outro". Deve agir com cautela diante de um genitor que afirma que seu(sua) filho(a) se queixa do tratamento dado pelo outro genitor quando da realização da visita, pois

[...]. Alterações no comportamento ou no humor de uma criança após um final de semana com o visitante costumam ser mencionados. Afinal, a visita, além de alterar a rotina, é o momento em que a criança vivencia fortemente a realidade da separação dos pais, podendo provocar reação de tristeza e desamparo. (Valente, 2008a, p. 76)

Conforme adverte Valente (2008a, p. 72) "a descrição da SAP deve ultrapassar as fronteiras da medicina e das ciências do comportamento, cabendo aos profissionais engajados na proteção à criança e à família alargar o conceito forjado por Gardner".

A nosso ver, a(o) assistente social deve trazer à tona os processos sociais relacionados ao convívio, à construção dos laços familiares e comunitários, à 
possibilidade de acesso dos indivíduos e famílias às políticas públicas e a história de vida dos envolvidos, a fim de que possibilitem uma percepção mais ampliada da questão pela autoridade judiciária para a tomada de decisão que melhor atenda aos interesses do envolvidos, sobretudo de crianças e adolescentes.

Reiteramos que é indispensável à(ao) profissional retornar aos aspectos teórico-metodológicos, ético-políticos e técnico-operativos, a fim de (re)estabelecer a ligação com o conteúdo profissional que os orienta. Logo, se comungamos com o projeto profissional crítico, que almeja uma nova ordem societária, não podemos desvincular a leitura sobre esse tema de elementos de análise, tais como o Estado (alargamento do Estado penal em detrimento do Estado social e a repercussão na vida dos indivíduos), o direito (em uma perspectiva radical que considere seus limites estruturais no contexto da sociedade capitalista, logo dos limites das normas que visam enquadrar os comportamentos dos indivíduos numa lógica binária e de soluções simplistas) e toda a avalanche de transformações sociais que perpassou e vem perpassando a família e que compõem o pano de fundo das relações familiares que, uma vez não resolvidas ou equacionadas no âmbito da própria família, são judicializadas na expectativa de soluções milagrosas.

Recebido em 21/6/2016 - Aprovado em 16/2/2017

\section{Referências bibliográficas}

BARROCO, M. L. S.; TERRA, S. H. Código de ética do/a assistente social comentado. São Paulo: Cortez, 2012.

IAMAMOTO, M. V. As dimensões ético-políticas e teórico-metodológicas no Serviço Social contemporâneo. In: XVIII SEMINÁRIO LATINOAMERICANO DE ESCUELAS DE TRABAJO SOCIAL. Serviço Social e Saúde: formação e trabalho profissional. San José12 jul. 2004. Texto originalmente publicado nos Anais do referido seminário: . Renovação e conservadorismo no Serviço Social: ensaios críticos. 8. ed. São Paulo: Cortez, 2007. 
IAMAMOTO, M. V. Serviço Social em tempo de capital fetiche: capital financeiro, trabalho e questão social. 2. ed. São Paulo: Cortez, 2008.

. Questão social, família e juventude: desafios do trabalho do assistente social na área sociojurídica. In: SALES, M. A.; MATOS, M. C. de; LEAL, M. C. (Orgs.). Política social, família e juventude: uma questão de direitos. São Paulo: Cortez, 2010. MOLINA, M. L. M. (Org.) La cuestión social y la formación profesional en el contexto de las nuevas relaciones de poder y la diversidad latinoamericana. San José: Alaets/ Espacio Ed./Escuela de Trabajo Social, 2004. p. 17-50, mimeo.

NETTO, J. P. A construção do Projeto Ético-Político do Serviço Social. In: MOTA, Ana E. Simões da et al. Serviço Social e Saúde: formação e trabalho profissional. São Paulo: Cortez, 1999.

. Capitalismo monopolista e Serviço Social. 4. ed. São Paulo: Cortez, 2005.

PIZZOL, A. D. Estudo social ou perícia social? Um estudo teórico-prático na Justiça catarinense. 2. ed. rev. Florianópolis: Insular, 2006.

SILVA, M. N. da. Breves notas sobre o trabalho profissional: competências e atribuições na área sociojurídica. Em Pauta, Rio de Janeiro, v. 10, n. 29, 2012.

SOUZA, M. F. A participação do assistente social na judicialização dos conflitos sociais. Ser Social, Brasília, n. 19, 2006.

TRINDADE R. L. P.; SOARES, A. C. F. Saber e poder do assistente social no campo sociojurídico. In: XIV CONGRESSO BRASILEIRO DE SOCIOLOGIA, 2009, Rio de Janeiro. Anais eletrônicos do XIV Congresso Brasileiro de Sociologia. Disponível em: $<$ http://www.sbsociologia.com.br>. Acesso em: 18 jan. 2015.

VALENTE, M. L. C. S. Síndrome da alienação parental: a perspectiva do Serviço Social. In: ASSOCIAÇÃO DE PAIS E MÃES SEPARADOS (Org.). Síndrome da alienação parental e a tirania do guardião: aspectos psicológicos, sociais e jurídicos. Porto Alegre: Equilíbrio, 2008a.

. Famílias em litígio: o olhar do Serviço Social sobre os processos de ruptura. Tese (Doutorado) - Programa de Pós-Graduação em Serviço Social do Departamento de Serviço Social, Pontifícia Universidade Católica do Rio de Janeiro, Rio de Janeiro, 2008b. 